Old Dominion University

ODU Digital Commons

$5-24-2021$

\title{
From Managing Nurses to Serving Nurses: The Case for Transfusing Nursing Management With Servant Leadership During the Global COVID-19 Pandemic
}

\author{
William P. Jimenez \\ Old Dominion University, wjimenez@odu.edu \\ Seterra D. Burleson \\ Old Dominion University \\ Matthew J. Haugh \\ Henry Ford Health System
}

Follow this and additional works at: https://digitalcommons.odu.edu/psychology_fac_pubs

Part of the Human Resources Management Commons, Industrial and Organizational Psychology Commons, Leadership Studies Commons, Nursing Administration Commons, and the Organizational Behavior and Theory Commons

\section{Original Publication Citation}

Jimenez, W. P., Burleson, S. D., \& Haugh, M. J. (2021). From managing nurses to serving nurses: The case for transfusing nursing management with servant leadership during the global COVID-19 pandemic. Industrial and Organizational Psychology: Perspectives on Science and Practice, 14(1-2), 280-285. https://doi.org/10.1017/iop.2021.57 accepted for inclusion in Psychology Faculty Publications by an authorized administrator of ODU Digital Commons. For more information, please contact digitalcommons@odu.edu. 


\title{
From Managing Nurses to Serving Nurses: The Case for Transfusing Nursing Management With Servant Leadership During the Global COVID-19 Pandemic
}

\author{
William P. Jimenez ${ }^{1}$, Seterra D. Burleson ${ }^{1}$, and Matthew J. Haugh ${ }^{2}$ \\ ${ }^{1}$ Department of Psychology, Old Dominion University \\ ${ }^{2}$ Henry Ford Health System
}

\begin{abstract}
Author Note
William P. Jimenez (iD https://orcid.org/0000-0003-1141-4631
\end{abstract}

The views expressed in this commentary are those of the authors, and they do not necessarily reflect the views of Henry Ford Health System. We have no conflicts of interest to disclose. The authors would like to thank Mariluz G. Jimenez, RN for her helpful comments during the development of this paper.

Correspondence concerning this article should be addressed to William P. Jimenez, Old Dominion University, Department of Psychology, Mills Godwin Building 250, Norfolk, VA 23529, United States. Email: wil.p.jimenez@gmail.com

This article has been accepted for publication in a revised form in Industrial and Organizational Psychology: Perspectives on Science and Practice https://doi.org/10.1017/iop.2021.57. This version is free to view and download for private research and study only. Not for re-distribution, re-sale or use in derivative works. (C) The Author(s), 2021. 


\section{From Managing Nurses to Serving Nurses: The Case for Transfusing Nursing Management With Servant Leadership During the Global COVID-19 Pandemic}

[The nurse] could not, however, wear her mask in the hallways, or the cafeteria or any of the hospital's common areas, because her supervisors told her it would scare patients. "I was told if I wanted to wear a mask, I would not be working there," she said. "So I said I'm not willing to put my life at risk, and my contract was terminated."

—Davenport et al. (2020)

Nurses have risen to the occasion combating COVID-19 head-on. Around the world, they have been recognized as heroes for their work on the front line (e.g., Natarajan et al., 2020). But with the relentless onslaught of COVID- $19^{1}$ and a widespread shortage of adequate personal protective equipment (PPE; e.g., National Nurses United, 2020), nurses find themselves in incredibly hazardous work environments. In their focal article on pandemics and industrialorganizational (I-O) psychology, Rudolph et al. (2021) mention that during a disease outbreak, healthcare workers, especially nurses, are susceptible to experiencing increased strain that may result in risky behaviors (e.g., poor hand hygiene) and decreased well-being. Yet, nurses are expected to demonstrate resilience during crises — an expectation that some nursing scholars contend offloads occupational well-being responsibilities from the healthcare organization to the individual nurse (Maben \& Bridges, 2020). Additionally, nurses working during the COVID-19 pandemic also face stressors in the form of questionable healthcare administration practices that imply a lack of supervisor support (e.g., Davenport et al., 2020).

\footnotetext{
${ }^{1}$ 278.7 COVID-19-associated hospitalizations per 100,000 population in the United States (overall cumulative rate) and 70 million cumulative cases and 1.6 million cumulative deaths worldwide at the time of writing in December 2020 (Centers for Disease Control and Prevention [CDC], 2020b; World Health Organization [WHO], 2020).
} 
It is evident that nurses require more support and that now, more than ever, good leadership is needed in nursing management. Indeed, in a recent nursing journal editorial on COVID-19, the editors emphasized the importance of leader-provided support for nurses amid the pandemic (Maben \& Bridges, 2020). We agree with Rudolph et al. that endeavoring to conceptualize "a novel 'COVID-19 pandemic crisis leadership behavior' construct” (p. 35) would be a waste of resources. Thus, from an I-O psychology perspective, we focus on applying servant leadership — which is naturally aligned with the values, roles, and responsibilities of healthcare professionals - to nursing management so that nurses can receive the support they need during the COVID-19 pandemic and future health crises.

\section{Servant Leadership and Nursing Management During the COVID-19 Pandemic}

Demonstrating concern, respect, and appreciation for followers and caring about followers' welfare are leadership behaviors that are particularly important for leader effectiveness and followers' job attitudes and motivation (Judge et al., 2004). Consideration and concern for followers underlie servant leadership, defined as "an (1) other-oriented approach to leadership (2) manifested through one-on-one prioritizing of follower individual needs and interests, (3) and outward reorienting of their concern for self towards concerns for others within the organization and the larger community" (Eva et al., 2019, p. 114, emphasis in original). Previous research suggests that servant leadership positively impacts work engagement, organizational identification, and psychological empowerment during times of uncertainty across cultures and contexts (see de Sousa \& van Dierendonck, 2014). According to some scholars, focusing on individual servant leadership dimensions does not adequately capture the leadership construct's complexity (e.g., Liden et al., 2015). Thus, we discuss the application 
of seven core servant leadership dimensions to improve nursing management effectiveness during the COVID-19 pandemic.

1. Servant leaders engage in emotional healing when they are sensitive to their followers' personal concerns and well-being (Liden et al., 2008). Although this dimension of servant leadership aligns with nurses' treatment of patients, whose health and emotional needs are paramount, nurses do not always receive the same treatment from their leaders. With the ongoing nursing shortage (Marć et al., 2019) amplified by healthcare organizations experiencing COVID-19-related staffing shortages (CDC, 2020c), a servant leader nurse manager should prevent and remedy staffing issues by coordinating schedules with staff nurses while actively considering these nurses' individual needs and preferences.

2. The servant leader puts their followers first - even above themself or the organization (Liden et al., 2008). As with emotional healing, this servant leadership behavior clearly aligns with patient care. Nurses often skip mealtime breaks and even bathroom breaks during a shift because they are busy attending to patients, whose needs are top priority. In opposition to the hospitality approach to healthcare many healthcare systems have adopted (e.g., Rosenthal, 2013), the servant leader nurse manager would recognize, particularly during a pandemic, that although patient satisfaction is important, providing staff nurses with resources so that their needs are met will ultimately result in superior patient care. For example, staff nurses should be encouraged to take their breaks with managers stepping in to relieve these nurses and care for patients - despite COVID-19 pandemic requirements to doff and don PPE and wash hands more frequently before and after breaks taking up extra time.

3. Although to servant leaders meeting organizational objectives is actually secondary to meeting followers' needs (Stone et al., 2004), servant leaders remain knowledgeable of their 
organizations' goals as well as what is required to perform one's job well (Liden et al., 2008). Having such conceptual skills enables leaders to solve problems and help their followers and organization succeed (Liden et al., 2015). Nurse managers were staff nurses before they were managers; therefore, they are uniquely able to consider both the organization's and their followers' goals as they work to address pandemic-related issues. For example, a servant leader nurse manager understands that even amid widespread PPE shortages, their staff nurses require proper PPE to feel safe and provide proper care. In light of their healthcare facility's inability to obtain adequate PPE, a servant leader nurse manager should make use of their conceptual skills to advocate to hospital leadership for the decontamination and reuse of PPE per CDC (2020a) recommendations.

4. Servant leaders help followers grow and succeed (Liden et al., 2015). To that end, a servant leader nurse should consider advocating for nurse educators and nurse preceptors to receive formal training on how to train their fellow nurses effectively or even take on an active role in such training. I-O psychologists have identified "training the trainer" as a best practice for improving on-the-job training (e.g., Derouin et al., 2005), and some nursing programs have implemented such training for their clinical faculty (e.g., Bell-Scriber \& Morton, 2009). Effective training is especially important for preparing nurses and other healthcare professionals to successfully navigate emergency scenarios (e.g., see Fung et al., 2015). Thus, servant leader nurse managers should ensure that trainers and trainees are receiving effective training to improve patient care during COVID-19 and to better prepare nurses for future health crises.

5. Behaving ethically involves acting in a way that is honest and trustworthy and modeling this behavior for others (Liden et al., 2015). Beyond considering the importance of ethical 
practices with regard to patient care, it is essential that the servant leader nurse manager demonstrates awareness and concern for ethical considerations regarding the nurses under their supervision. Despite various personal and family needs and vulnerabilities and limited access to essential resources such as PPE, nurses have been called on to put themselves at increased risk during the COVID-19 pandemic. Thus, it is critical for nurse managers to clarify employer and employee expectations during the pandemic and effectively communicate with and support followers without threat of retaliation for raising concerns (American Nurses Association [ANA], n.d.).

6. Empowering followers occurs when leaders delegate responsibility to followers, support followers' autonomy in executing work tasks, and allow followers to influence decisionmaking (Liden et al., 2015). Nurses' job autonomy is positively related to employee outcomes such as job satisfaction and turnover intention (Nei et al., 2015; Zangaro \& Soeken, 2007). Yet, healthcare employees, even under typical circumstances, face many work demands, and they often have little job control and strictly scheduled work hours as a result of regulated nurse-patient ratios (Odle-Dusseau et al., 2016). Many nurses lack adequate support for meeting personal and family needs, are in a vulnerable population themselves, or have personal concerns regarding the provision of care during health crises (ANA, n.d.). Further, many hospitals are imposing visitor restrictions (e.g., requiring face coverings), and nurses are left to enforce these restrictions with little support from leaders. To empower followers, the servant leader nurse manager should provide a reasonable degree of flexibility and autonomy in solving scheduling or assignment issues through negotiation with other nurses and demonstrate support for nurses' decisions regarding the enforcement of visitor restrictions. For example, nurses who do not have vulnerable household members may 
be willing to volunteer to work in place of those who have family members that are especially vulnerable during a pandemic, and nurse managers could get involved or encourage staff nurses to directly contact security when visitors refuse to comply with staff nurses' face-covering requests.

7. Creating value for the community encompasses leaders' efforts to give back to the community surrounding the organization while encouraging followers to do so as well (Liden et al., 2015). By healing community members during the COVID-19 pandemic, nurses are directly creating value for their communities. As nurse managers are healthcare professionals themselves, this dimension of servant leadership is readily applicable to nursing management. For example, the servant leader nurse manager could demonstrate care for the community by encouraging other nurses, patients, families, and the broader community to do their part to prevent community spread by physically distancing, wearing face coverings, and engaging in general hygiene practices. Doing so also shows that the manager puts their staff nurses first by protecting followers as well as other frontline workers who will in turn safely continue to serve the community. The servant leader nurse manager could also create value for the community during the pandemic by volunteering their skills and knowledge to assist community members who are in need while encouraging their staff nurses to do the same (see ANA Enterprise, n.d.).

Although servant leadership has appeared in the nursing management literature (e.g., Neill \& Saunders, 2008), this leadership style seems to be absent from actual nursing management practice during the COVID-19 pandemic. In fact, nursing does not seem to place an emphasis on nursing leadership in general (e.g., Leininger, 1974). Many nurse managers are staff nurses who outgrew floor nursing. They are often promoted to leadership positions as a result of 
accumulated experience in the field and/or organizational politics as opposed to their demonstration of actual leadership skills or potential. Their management training often exclusively comes in the form of annual corporate training classes offered to all leaders in the healthcare organization. Although there is a need for formal nurse leadership training and development programs (see Broom, 2020), nurses' professional values (e.g., human dignity, integrity, altruism, justice; Schmidt \& McArthur, 2017) are clearly aligned with the principles of servant leadership (Fahlberg \& Toomey, 2016). Recent calls for nursing management to seriously consider adopting a servant leadership philosophy (e.g., Tropello \& DeFazio, 2014) and the increased recognition of nurses during health crises suggest that it is time for nurse managers and other healthcare leaders to consider shifting their focus from patient satisfaction to serving nurses. As hospitals are vital to community health and are in desperate need of skilled healthcare professionals to serve the public in a pandemic, serving nurses will enable hospitals to stay ahead of the increased demand for beds and ultimately better serve the community.

\section{Concluding Remarks}

Rudolph et al. (2021) conclude their focal article with a call to action for I-O psychologists to innovatively address work-related issues during COVID-19 and future health crises. We contend that during health crises, servant leadership is especially important for nurses, other healthcare professionals, and other frontline workers. We encourage I-O psychologists to bring best practices to nursing management and healthcare administration by actively partnering — for example, through collaborative research or consulting — with healthcare organizations. We believe that servant leadership can provide nurses—who, along with midwives, constitute approximately half of the global healthcare workforce (WHO, 2016) —with much-needed support during the global COVID-19 pandemic and future health crises. 


\section{References}

American Nurses Association. (n.d.). Nurses, ethics and the response to the COVID-19 pandemic. https://www.nursingworld.org/ 495c6c/globalassets/practiceandpolicy/workenvironment/health--safety/coronavirus/nurses-ethics-and-the-response-to-the-covid-19pandemic.pdf

ANA Enterprise. (n.d.). Volunteer. https://www.nursingworld.org/practice-policy/workenvironment/health-safety/disaster-preparedness/coronavirus/get-involved/volunteer

Bell-Scriber, M. J., \& Morton, A. M. (2009). Clinical instruction: Train the trainer. Nurse Educator, 34(2), 84-87. https://doi.org/10.1097/NNE.0b013e31819ae753

Broom, D. (2020, July 22). The world needs 6 million new nurses by 2030. https://www.weforum.org/agenda/2020/07/world-nursing-report-recruitment-shortageswho-2030/

Centers for Disease Control and Prevention. (2020a, October 19). Decontamination and reuse of filtering facepiece respirators. https://www.cdc.gov/coronavirus/2019-ncov/hcp/ppestrategy/decontamination-reuse-respirators.html

Centers for Disease Control and Prevention. (2020b, December 11). Key updates for week 49, ending December 5, 2020. https://www.cdc.gov/coronavirus/2019-ncov/coviddata/pdf/covidview-12-11-2020.pdf

Centers for Disease Control and Prevention. (2020c, December 14). Strategies to mitigate healthcare personnel staffing shortages. https:/www.cdc.gov/coronavirus/2019ncov/hcp/mitigating-staff-shortages.html

Davenport, C., Bhattarai, A., \& McGregor, J. (2020, March 31). As coronavirus spreads, so do reports of companies mistreating workers. The Washington Post. 
https://www.washingtonpost.com/business/2020/03/31/worker-retaliation-mistreatmentcoronavirus/

de Sousa, M. J. G., \& van Dierendonck, D. (2014). Servant leadership and engagement in a merge process under high uncertainty. Journal of Organizational Change Management, 27(6), 877-899. https://doi.org/10.1108/JOCM-07-2013-0133

Derouin, R. E., Parrish, T. J., \& Salas, E. (2005). On-the-job training: Tips for ensuring success. Ergonomics in Design: The Quarterly of Human Factors Applications, 13(2), 23-26. https://doi.org/10.1177/106480460501300206

Eva, N., Robin, M., Sendjaya, S., van Dierendonck, D., \& Liden, R. C. (2019). Servant leadership: A systematic review and call for future research. The Leadership Quarterly, 30(1), 111-132. https://doi.org/10.1016/j.leaqua.2018.07.004

Fahlberg, B., \& Toomey, R. (2016). Servant leadership: A model for emerging nurse leaders. Nursing: The Peer-Reviewed Journal of Clinical Excellence, 46(1), 49-52. https://doi.org/10.1097/01.NURSE.0000494644.77680.2a

Fung, L., Boet, S., Bould, M. D., Qosa, H., Perrier, L., Tricco, A., Tavares, W., \& Reeves, S. (2015). Impact of crisis resource management simulation-based training for interprofessional and interdisciplinary teams: A systematic review. Journal of Interprofessional Care, 29(5), 433-444. https://doi.org/10.3109/13561820.2015.1017555

Judge, T. A., Piccolo, R. F., \& Ilies, R. (2004). The forgotten ones? The validity of consideration and initiating structure in leadership research. Journal of Applied Psychology, 89(1), 3651. https://doi.org/10.1037/0021-9010.89.1.36 
Leininger, M. (1974). The leadership crisis in nursing: A critical problem and challenge. Journal of Nursing Administration, 4(2), 28-34. https://doi.org/10.1097/00005110-19740300000022

Liden, R. C., Wayne, S. J., Meuser, J. D., Hu, J., Wu, J., \& Liao, C. (2015). Servant leadership: Validation of a short form of the SL-28. The Leadership Quarterly, 26(2), 254-269. https://doi.org/10.1016/j.leaqua.2014.12.002

Liden, R. C., Wayne, S. J., Zhao, H., \& Henderson, D. (2008). Servant leadership: Development of a multidimensional measure and multi-level assessment. The Leadership Quarterly, 19(2), 161-177. https://doi.org/10.1016/j.leaqua.2008.01.006

Maben, J., \& Bridges, J. (2020). Covid-19: Supporting nurses' psychological and mental health. Journal of Clinical Nursing, 29(15-16), 2742-2750. https://doi.org/10.1111/jocn.15307

Marć, M., Bartosiewicz, A., Burzyńska, J., Chmiel, Z., \& Januszewicz, P. (2019). A nursing shortage - A prospect of global and local policies. International Nursing Review, 66(1), 9-16. https://doi.org//10.1111/inr.12473

Natarajan, S., Lowen, M., \& Parkinson, C. (2020, May 11). Coronavirus: Four nurses on four continents tell their story. $B B C$. https://www.bbc.com/news/in-pictures-52616933

National Nurses United. (2020, November 12). National nurse survey exposes hospitals' knowing failure to prepare for a Covid-19 surge during flu season [Press release]. https://www.nationalnursesunited.org/press/national-nurse-survey-4-exposes-hospitalsknowing-failure-prepare-covid-19-surge 
Nei, D., Snyder, L. A., \& Litwiller, B. J. (2015). Promoting retention of nurses: A meta-analytic examination of causes of nurse turnover. Health Care Management Review, 40(3), 237253. https://doi.org/10.1097/HMR.0000000000000025

Neill, M. W., \& Saunders, N. S. (2008). Servant leadership: Enhancing quality of care and staff satisfaction. The Journal of Nursing Administration, 38(9), 395-400. https://doi.org/10.1097/01.NNA.0000323958.52415.cf

Odle-Dusseau, H. N., Hammer, L. B., Crain, T. L., \& Bodner, T. E. (2016). The influence of family-supportive supervisor training on employee job performance and attitudes: An organizational work-family intervention. Journal of Occupational Health Psychology, 21(3), 296-308. https://doi.org/10.1037/a0039961

Rosenthal, E. (2013, September 21). Is this a hospital or a hotel? The New York Times. https://www.nytimes.com/2013/09/22/sunday-review/is-this-a-hospital-or-a-hotel.html

Rudolph, C. W., Allan, B., Clark, M. Hertel, G., Hirschi, A., Kunze, F., Shockley, K., Shoss, M., Sonnentag, S., \& Zacher, H. (2021). Pandemics: Implications for research and practice in industrial and organizational psychology. Industrial and Organizational Psychology: Perspectives on Science and Practice, 14(1).

Schmidt, B. J., \& McArthur, E. C. (2017). Professional nursing values: A concept analysis. Nursing Forum, 53(1), 69-75. https://doi.org/10.1111/nuf.12211

Stone, A. G., Russell, R. F., \& Patterson, K. (2004). Transformational leadership versus servant leadership: A difference in leader focus. Leadership \& Organization Development Journal, 25(4), 349-361. https://doi.org/10.1108/01437730410538671

Tropello, P. D., \& Defazio, J. (2014). Servant leadership in nursing administration and academia shaping future generation of nurses and interdisciplinary team providers to transform 
healthcare delivery. Nurse Leader, 12(6), 59-66.

https://doi.org/10.1016/j.mnl.2014.09.010

World Health Organization. (2020, December 15). COVID-19 weekly epidemiological update. https://www.who.int/publications/m/item/weekly-epidemiological-update---15-december2020

World Health Organization. (2016). Global strategic directions for strengthening nursing and midwifery 2016-2020. WHO Press.

Zangaro, G. A., \& Soeken, K. L. (2007). A meta-analysis of studies of nurses' job satisfaction. Research in Nursing \& Health, 30(4), 445-458. https://doi.org/10.1002/nur.20202 